\title{
Coronavirus (COVID-19)"infodemic" in the Social Media: A Survey of Kenya International Students in China
}

\author{
Oloo Daniel Ong'ong'a \\ Institute of Communication Studies, Communication University of China, Beijing, China \\ John Demuyakor \\ Institute of Communication Studies, Communication University of China, Beijing, China
}

\begin{abstract}
In the modern world today, epidemics, disasters, and tragic information have dominated social media platforms. This space offers a wide range of diets that, to some extent, the distinction of what is credible information is embryotic to misinformation, disinformation, fake news, and mal-information. This field has continued to raise questions from the scholars in a wide range of spectrum in social science research. The study of misinformation in social media is a very multifaceted problem that draws different conception from different continuums in both academia and policymakers. Recently, there has been widespread misinformation coined with mal-information and infodemic in the various social media concerning the spread of Coronavirus not only in China but also in the rest of the world. This has raised debate from credible health organizations, the media, and the members of the public on the veracity of this information on social media platforms. Therefore, this study employed a survey as a method to investigate the strategies used by international students in China to debunk the misinformation about Coronavirus in various social media. The study suggests the implementation of various media literacy programs by different stakeholders to empower students to minimize and fight misinformation in multiple online spaces.
\end{abstract}

Keywords: Social media, misinformation, media literacy, COVID-19

DOI: $10.7176 / \mathrm{NMMC} / 90-03$

Publication date:May $31^{\text {st }} 2020$

\section{Introduction}

In the wake of 2020, China as a country faced another tragedy this time, not SARS (Severe Acute Respiratory Syndrome) or MARS (Middle East Respiratory Syndrome) but (WHO, 2020), a COVID-19 that originated from one of the cities in, Wuhan (FactCheck.org, 2020). This news was not taken lightly by the social media users who went farther to post all day to day operations as well as events in Wuhan. The information received from different social media platforms (Kaur, 2020), ensured that the world at large remained informed on the whereabouts of various individuals in the city and the country's preparedness in dealing with this kind of epidemic. As information spread far and wide, it entangles with different versions hence ending up (FactCheck.org, 2020; Herrera, 2020), distorted, or even creating a distinct curve on its dissemination. Herrera (2020) indicates that misinformation about Coronavirus is not near to end as major social media giant tools as goggle, twitter, and Facebook vowed to fight it on their platforms.

On the side, social media tools have the ability (Bryan \& Agnieszka, 2018, p. 136), to empower and turn into a double edge sword when malicious messages as well as rumors that concerns the health and wellbeing of people in the society are discussed openly without their knowledge or interest. The sudden death of the (Al Jazeera, 2020), a doctor who whistle blew the spread of the virus, marked the beginning of the spat of misinformation in various social media platforms not limited to the (Bryan \& Agnieszka, 2018, p. 136), highly censored Weibo and WeChat. The sharing of pictures, images, and well wishes information filled the platforms describing him as a hero, but other questions raised about his sudden death. Academics argue that false virus information is more damaging to individuals than malicious political misinformation because it creates panic and leads people to make (Herrera, 2020), a misinformed decision concerning their health. Although Facebook, like other social media, employed people throughout the world to determine the contents, whether it is misleading, it also employs the expertise of major health organizations in flagging the misleading content for removal (Herrera, 2020). Interesting to note that different social media like WhatsApp have message encrypted capabilities that hinder censorship or diversion of sensitive information from the companies even in the core of an acute or noxious international crisis (Romm, 2020). Therefore, this limits them to stop spreading misinformation created and shared by the users on such a social media platform.

Whenever such a kind of tragedy happens, it creates fears within people who seek to find truthful information from various available types of media and social platforms (Romm, 2020). Media at large have continued to utilize social media as their tool to spread information or even source for stories that they can use as their breaking news. This arrangement, it creates the veracity of news being consumed by the various individual who yearns for the information for their fulfillment. Since social media gives a variety of information diet, individuals jump from one site to others simultaneously to fact check, share, comment, or even create their version of the same piece of 
information according to their understanding and standing point. Despite social media removing some of the fraudulent posts, false information, and conspiracy theories have continued to proliferate in the online sphere (Herrera, 2020).

On this premise, we explored the student's perception of the debunking of the misinformation of Coronavirus in social media. International students use various social media platforms to stay connected with their families as well as relatives both inside and outside the university and their home country.

\section{Literature Review}

The Internet has changed the fortunes of the world (Bryan \& Agnieszka, 2018). Since its inception, academia, especially university students and lecturers, consider the Internet is ideal for achieving their set academic objectives. Another section of the society mainly uses the Internet for monitoring and consuming news on both new and traditional media platforms, such as some decades ago, people from all backgrounds have utilized it for different purposes. While captains of industries think the Internet helps them in promoting their businesses, those in social media, radio, TV, and newspapers in other to be abreast of the current happenings all over the globe (O'Connor \& Weatherall, 2019, pp. 8-12). As of January 2020, it is estimated that almost 4.54 billion of the world's population are active internet users. It is also cited that the global population internet will reach 5.3 billion users by 2023 , which equates to $66 \%$ of the entire(Statista.com, 2019).

A report by (Statista.com, 2019; e-marketers, 2019) revealed that about 3.5 billion people use the social media globally in 2019, which represents about $45 \%$ of the entire population of the world and it is projected to hit $66 \%$ of the world's population by the end of 2020 . Statista.com ( 2019$)$ reported that $81 \%$ of college or university students use social media worldwide in 2019. The social media platform frequently used by college and university students included but not limited to Facebook, WhatsApp, WeChat, Instagram, Snapchat, Twitter, and Weibo, among others. Globally, Facebook is reported to be the most widely used platform, with an estimated 2.5 billion active monthly users, as in the last quarter of 2019(Statista.com, 2019). Another study indicates that 74\% of college plus students in the USA(United States of America) were reported to have created profiles on Facebook and are active users(Statista.com, 2019).

Social media tools in contemporary times are considered as one of the vital channels of accessing authentic and reliable news. Still, in the same vein, social media is also considered as one the primary avenue for users to propagate fake news (Berghel, 2017). False news detection has become a topical and emerging issue that is attracting the attention of those within academia and media studies (Berghel, 2017). Detecting fake news is one of the challenging tasks due to two main reasons; thus, the non-verbal posture of the sender and the time-space the originator of such fake news have to carefully craft this message for onward consumption by the general public. Notwithstanding the complexities of identifying fake news, some researchers and media experts believe that, through the type of language used, it is easy to differentiate or detect real story from fake news. Most of these massages have less editorial elements in them and hence easily noticed.

NewsWhip (2018) has revealed that fake news continues to be one of the significant challenges on Facebook and other social media platforms, notwithstanding the policy decisions and interventions taken in the past. Since 2016, organizations in charge of fact-checking of false stories have reported that fake news on Facebook, as well as two other essential news site, have seen little or no reduction in misinformation (Funke, 2018). Media experts believe that the strategy of double-checking the source of the news item as a way of eliminating fake news cannot withstand the test of time (Levin, 2017) as the issue of deception of information is escalating to more enormous proportions in recent years(Ghosh and Scott 2018).

The past decade is has been described by experts as a revolution period for the circulation of false information and deception on social networking platforms across the world(Flynn et al., 2017; Lazer et al., 2018). According to (Allcott et al., 2018; Allcott \& Gentzkow, 2016) suggests that many adults who read or come across these fake stories turn to believe and have faith in them, hence sharing it with others. Scholars such as (Spohr, 2017; Azzimonti \& Fernandes, 2018), are of the view that fake stories and misinformation have and continued to shape a lot of significant events such as elections, political crises and natural disasters in the history of the world. In the bid to find some considerable solutions to this unfortunate phenomenon of misinformation, some social media companies such as Facebook have taken some policy initiatives to reduce the rapid spread of false news content, especially after the 2016 US general elections. The question is whether this policy change has made the desired impact is still unanswered.

Traditional media platforms such as TV, radio, and newspapers in the immediate past were seen and classified us the preferred choice when it comes to authentic news broadcast (Abdenour, 2017). Traditional media sources were the trusted channels of news for the majority of the world population, simply because they followed strict code, regulations, and editorial standards of practice guiding journalism in producing news content for public consumption. Unfortunately, in traditional media quest to compete with the new media platforms in breaking news headlines and attracting a broad audience, most of the traditional media outlets now basically depend on social media for news stories(Gearhart \& Kang, 2015). Most of the traditional media news outlets copy news items from 
social media without authenticating the genuineness of such news before putting in the public domain for consumption (Abdenour, 2017).

When people read the news, stories begin to have a particular interest and associate themselves with the account, it is likely they might create or spread the news item for others to consume. Some scholars have proposed the following skills in identifying fake news. These include and not limited to Fact-checking, thus cross-checking with other similar stories in different media outlets to ascertain the worth of the news item. Media literacy is another skill in identifying fake news. It entails the practice of accessing and critically evaluating media content and determining how media content can sometimes be manipulated for self-fish interest. The final but not least skill of identifying fake news is the simplicity of stories reported by fake news creators, which can easily be measured through the readability index and the intensity of emotions based on valence (Lazer et al., 2018).

Since the outbreak of the deadly Coronavirus(COVID-19) in Wuhan a city in China, in December 2019 and the subsequent declaration of the respiratory disease as Public Health Emergency of International Concern (PHEIC) by World Health Organisation (WHO), many groups and individual continue to spread and circulate false rumors and (Herrera, 2020; Kaur, 2020), misinformation about the virus on platforms such as Facebook, WhatsApp and WeChat across the world (WHO, 2020). As WHO and governments around the globe, especially those in China are working assiduously in finding a lasting cure to the COVID-19, a prime obstacle that is a hindrance to their gains made and in no small extent discouraging to most health experts is the misinformation on social media and other news media which has been termed as infodemics (WHO, 2020). Most of the misinformation and false claims on the virus originates from social media platforms (Herrera, 2020; Kaur, 2020). Some of the outrageous claims even suggest that the virus was purposely manufactured in the laboratory, and the vaccine for it was already in circulation (FactCheck.org, 2020; Kaur, 2020; Romm, 2020).

Linguist and media literacy scholars call the use of language types as the lexical structure. It is the unreliable and bias piece of information that is usually related to some structural and linguistic cues. This cue includes the use of hedges, active verbs and subjective intensifiers which makes the piece of information bias and gears towards achieving personal interest (Berghel, 2017; Recasens et al., 2013; Rubin et al., 2016)Other elements of identifying that a news reportage is "fake" or has the aspects of misinformation in social media according to some media experts are, "reading only the heading". Generally, such news headlines are distorted and misleading. People who read only the headlines of a news story tend to spread falsehood and can mislead other readers. Media experts have advised that an in-depth reading and understanding of the content of a news item be done before spreading it for others to consume. In simple terms, one must always be encouraged to read beyond the headlines to avoid spreading fake news(FactCheck.org, 2020; Kaur, 2020; Romm, 2020). The second element of identifying fake news is "reading the whole story and making judgments". This has to do with the tendency of been subjective upon reading a news story.

\subsection{Theoretical Framework}

To investigate the issues in the study, we utilized conspiracy theory which embeds itself with misinformation. Conspiracy theory explains the phenomenon of people trying to coin opinions and explanations to the actual cause of an event, either political or social, to suit their interests(Douglas et al., 2019; Kovic \& Füchslin, 2018; Lewandowsky \& Cook, 2020). Scholars such as (Lewandowsky \& Cook, 2020) have argued that conspiracies exist, although they are rarely discovered through the methods of conspiracy theorists. Conventional thinking is critical in checking the official accounts while considering the availability of evidence that are internally consistent (Jolley et al., 2019). People transmit news or information at their disposal using conspiracy theories (Douglas et al., 2019). Since the outbreak of the Coronavirus, several people have made false claims concerning the origin and mode of spreading of the dangerous virus (WHO, 2020). Conspiracy theories about the Coronavirus fall under broad forms, misinformation about the origin of the virus, and theories on how the disease can be the cure. Wood (2018) suggests that conspiracy theories spread quickly and widely through a decentralized network, which of these are social media platforms. Therefore, this theory is adopted in this study to find out how students perceive misinformation and fake news on COVID-19 in social media platforms.

3.

Base on the literature review, the following questions serve as a guide to the study:

\section{Research Question}

RQ1. What is the perception of international students regarding news as "Fake"?

RQ2. What social media platform(s) do students encounter fake news about COVID-19?

RQ3. What strategies do students use to identify news on COVID-19 as "fake" in social media?

RQ4. What skills do students pose in detecting misinformation and fake news on COVID-19 in social media?

RQ5. How do students describe the current messages about COVID-19 in social media? 
RQ6. What reliable sources do students access information on COVID-19?

\section{Methodology}

This article adopted a purposive online survey of international students from one of the online communities. Stimson (2014) posits that online surveys are a relatively less expensive way of soliciting real-time data from online participants. The data were collected between January and February 2020. The online questionnaire tool for data collection was developed and randomly sent to a WeChat group for the international student for the pre-test, as argued by (Presser et al., 2004, p. 525). This allowed for the verification of the information as well as the grammar and whether some of the questions needed clarification. After the questionnaires were returned, the adjustments observed were aligned to suit the study at hand. The survey was then sent to the WhatsApp group (see for details about WhatsaAPP, Bryan \& Agnieszka, 2018, p. 131) of the international students from Kenya studying in China. This kind of social media has been linked to having the ability to share and create information in small groups (Ndlela \& Mano, 2020, p. 162).

\subsection{Sampling}

Since the group is made up of 256 people but with 213 active members (members in the group who actively participate in commenting, asking the question, sharing various information in the group to ensure that group remains active), all the active participants were targeted for the survey. Before subjecting the participants to the esurvey, a request was made to both the group administrators and members on the intent of the survey. After the consent was reached with the support of the group administrators, the link to the survey was shared in the WhatsApp group platform.

The survey took the participants about 7 minutes to complete, which comprised 25 mixed questions. These included three sections; participants general information, media use in communicating news; COVID-19 information, and messaging with discrete, multiple, and open-ended questions. The weekly reminder strategy was used to inform the participants who had not completed the survey to do so. The total final sample of 197 was used for this article with a response rate of $92.49 \%$. A descriptive statistic method enabled this study to achieve the principles of reliability and objectivity, which are critical elements in statistical data analysis ( Kemp et al., 2018, p. 3).

\section{Findings}

The outcomes of this research are discussed and presented base on the questions of this study indicated earlier. The purpose of this research is to investigate misinformation about (COVID-19) on social media. Data received from respondents were computed and evaluated into quantitative forms utilizing statistical package for social sciences (SPSS) version 20. The study uses frequencies and percentages, inputting the data into various categories. In order to measure the reliability among variables of the survey, SPSS was used.

\subsection{Response Rate}

Scholars such as (Babbie, 2017; Bryman, 2012; Singh, 2007), cited that when the all the target respondents of a study respond to the questionnaire and the actual valid data is obtained, then it is described as the response rate. To get the response rate, we sum the questionnaire collected and divided it by the actual population sample for the study. KoBo Toolbox was used to manage the data for this study. In all, 213 questionnaires were answered, of which 197 of them were valid. This represented a 92.49\% response rate. (Berghel, 2017; Recasens et al., 2013; Rubin et al., 2016) cited that any study with a response rate of 50\% and above is appropriate for analysis, hence our response rate of $92.49 \%$ was very excellent to continue with the investigation.

\section{Demographic Characteristics of Respondents 7.1 Gender of Respondents}

As part of finding answers to the research objective, the gender distribution of the respondents was essential. The analysis of the collected data indicated that $55.8 \%$ of our sampled participants were male, $44.2 \%$ were female. This gender distribution is presented in figure 1 below. It was, however, essential to indicate that gender disparities have no likelihood of affecting the outcomes of this study. The questions for the study were not gender-sensitive; hence room has been created for any error that might arise as a result of the gender imbalance. Also, it essential to acknowledge that misinformation about the COVID-19 does not depend on a number of gender responses somewhat is expected to accommodate the perceptions and opinions of either gender. 
Figure 1: Gender distribution of respondents

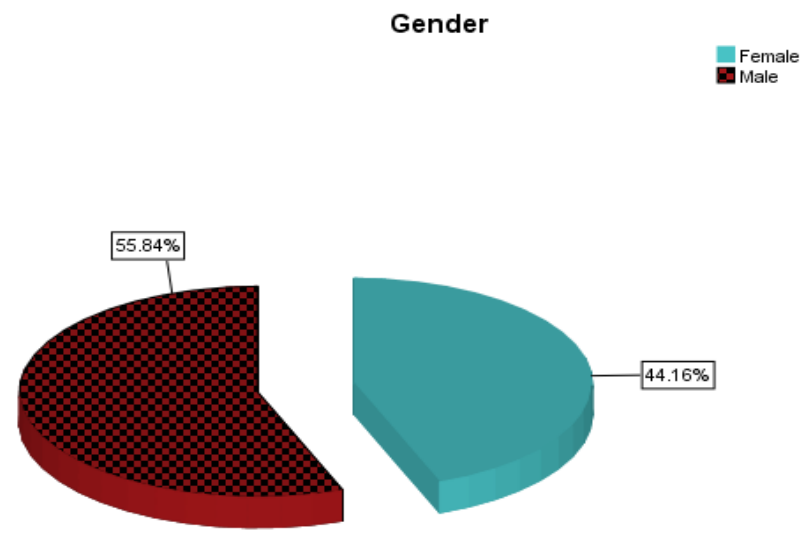

7.2 The Age Distribution of Participants

The age distributions of respondents were also essential for this study. The analysis of the data presented the following picture: $32.5 \%$ of the sampled populations were aged $26-30,27.4 \%$ are within $31-35$ years, and those within $18-25$ years were 17 . \%. Those within $36-40$ years were $15.7 \%$, and $7.1 \%$ of the respondents were 41 years and above. This is represented in figure 2 below.

Figure 2: Age Distribution of Participants

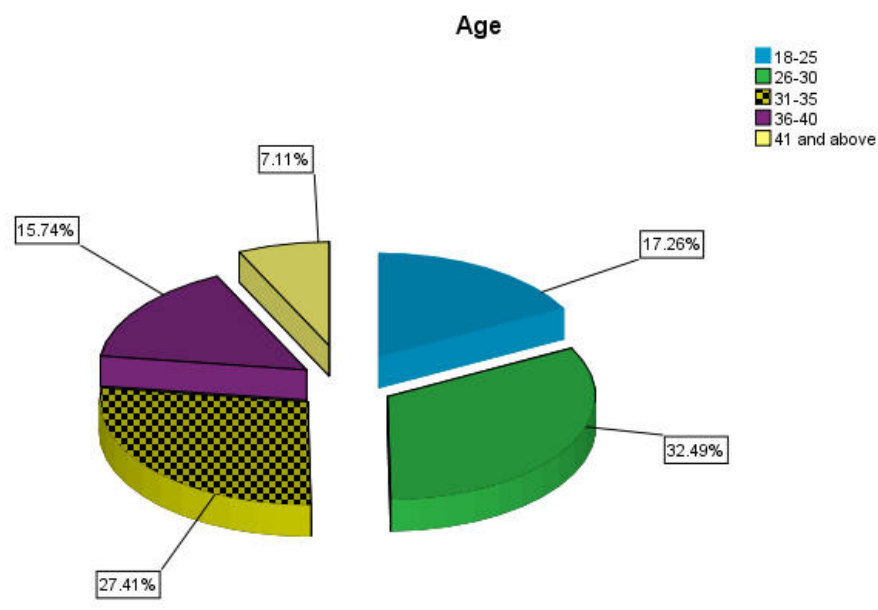

\section{Media Use In Communicating News}

The finding in Table 1 indicate responses from respondents on the media use in communicating news

\subsection{The perception of Students Regarding News as "Fake."}

Table 1 of the study explains the total number of respondents, along with the frequency of each choice. $16.8 \%$ of the respondents defined "fake" news as Misinformation, $13.2 \%$ of the respondents' propaganda, $8.6 \%$ lies, $8.1 \%$ lies, hoaxes, misinformation and propaganda, 5.6\% lies, hoaxes, misinformation, conspiracies and propaganda, $12.7 \%$ misinformation, and propaganda, $13.7 \%$ misinformation, conspiracies and propaganda, $19.3 \% 1$ lies misinformation and conspiracies and $2.0 \%$ hoaxes. 


\begin{tabular}{|c|c|c|c|c|}
\hline & Frequency & Percent & $\begin{array}{l}\text { Valid } \\
\text { percent }\end{array}$ & $\begin{array}{l}\text { Cumulative } \\
\text { percent }\end{array}$ \\
\hline Misinformation & 33 & 16.8 & 16.8 & 16.8 \\
\hline Propaganda & 26 & 13.2 & 13.2 & 29.9 \\
\hline Lies & 17 & 8.6 & 8.6 & 38.6 \\
\hline Lies, hoaxes, misinformation, and propaganda & 16 & 8.1 & 8.1 & 46.7 \\
\hline $\begin{array}{l}\text { Lies, deceptions, misinformation, } \\
\text { conspiracies, and propaganda }\end{array}$ & 11 & 5.6 & 5.6 & 52.3 \\
\hline Misinformation and propaganda & 25 & 12.7 & 12.7 & 65.0 \\
\hline Misinformation, conspiracies, and propaganda & 27 & 13.7 & 13.7 & 78.7 \\
\hline Lies, misinformation, and conspiracies & 38 & 19.3 & 19.3 & 98.0 \\
\hline Hoaxes & 4 & 2.0 & 2.0 & 100.0 \\
\hline TOTAL & 197 & 100.0 & 100.0 & \\
\hline
\end{tabular}

8.2. Social Media Platform(s) that Students Encounter Fake News about (COVID-19) From the table 2 below, $5.1 \%$ said they encounter fake news from Weibo, $2.5 \%$ of the respondents encounter fake news from Facebook and WhatsApp, 3.0\% Weibo and WeChat, 19.3\% WeChat, Facebook, Twitter and WhatsApp, 5.6\% WeChat only, 10.2\% Facebook only, 5.1\% Pinterest, 4.1\% Twitter only, 18.3\% WhatsApp only, 3.6\% LinkedIn, 16.2\% WeChat, Facebook and WhatsApp and 7.1\% Facebook, WhatsApp and Twitter.

Table 2: Social media platform(s) that students encounter fake news about (COVID-19)

\begin{tabular}{|c|c|c|c|c|}
\hline & Frequency & Percent & $\begin{array}{l}\text { Valid } \\
\text { percent }\end{array}$ & $\begin{array}{l}\text { Cumulative } \\
\text { percent }\end{array}$ \\
\hline Weibo & 10 & 5.1 & 5.1 & 5.1 \\
\hline Facebook and WhatsApp & 5 & 2.5 & 2.5 & 7.6 \\
\hline Weibo and WeChat & 6 & 3.0 & 3.0 & 10.7 \\
\hline $\begin{array}{l}\text { WeChat, Facebook, Twitter, and } \\
\text { WhatsApp }\end{array}$ & 38 & 19.3 & 19.3 & 29.9 \\
\hline WeChat & 11 & 5.6 & 5.6 & 35.5 \\
\hline Facebook & 20 & 10.2 & 10.2 & 45.7 \\
\hline Pinterest & 10 & 5.1 & 5.1 & 50.8 \\
\hline Twitter & 8 & 4.1 & 4.1 & 54.8 \\
\hline WhatsApp & 36 & 18.3 & 18.3 & 73.1 \\
\hline LinkedIn & 7 & 3.6 & 3.6 & 76.6 \\
\hline WeChat, Facebook, and WhatsApp & 32 & 16.2 & 16.2 & 92.9 \\
\hline Facebook, WhatsApp, and Twitter & 14 & 7.1 & 7.1 & 100.0 \\
\hline TOTAL & 197 & 100.0 & 100.0 & \\
\hline
\end{tabular}

\subsection{Strategies Students use to Identify News on (COVID-19) as "Fake" in Social Media}

In Table 3 of the study illustrate the total number of the respondent, which is 197 . The table also has a frequency of each choice such as 'Reading the whole story and making judgments' 36 (18.3\%) 'Facts checking with other similar stories in different media' $30(15.2 \%)$ 'Reading the whole story and making judgment and facts checking with other related stories I mixed media' $41(20.8 \%)$ 'Reading the whole story and making a judgment, reading and following comments and facts checking with other similar stories in different media' 31 (15.7\%) 'Reading the headline alone, reading the whole story and making judgment and reading and following comments' 32 (16.2 \%) 'Reading the headline alone, Reading the whole story and making judgment and reading and following comments' 27 with (13.7\%). 


\begin{tabular}{|c|c|c|c|c|}
\hline & Frequency & Percent & $\begin{array}{l}\text { Valid } \\
\text { Percent }\end{array}$ & $\begin{array}{l}\text { Cumulative } \\
\text { Percent }\end{array}$ \\
\hline Reading the whole story and making judgments & 36 & 18.3 & 18.3 & 18.3 \\
\hline $\begin{array}{l}\text { Facts checking with other similar stories in } \\
\text { different media }\end{array}$ & 30 & 15.2 & 15.2 & 33.5 \\
\hline $\begin{array}{l}\text { Reading the whole story and making judgment } \\
\text { and facts checking with other similar stories in } \\
\text { different media }\end{array}$ & 41 & 20.8 & 20.8 & 54.3 \\
\hline $\begin{array}{l}\text { Reading the whole story and making judgment } \\
\text { reading and following comments and facts } \\
\text { checking }\end{array}$ & 31 & 15.7 & 15.7 & 70.1 \\
\hline $\begin{array}{l}\text { Reading the headline alone, reading the whole } \\
\text { story and making the judgment, reading and } \\
\text { following comments }\end{array}$ & 32 & 16.2 & 16.2 & 86.3 \\
\hline $\begin{array}{l}\text { Reading the headline alone, reading the whole } \\
\text { story and making judgment and reading and } \\
\text { following comments }\end{array}$ & 27 & 13.7 & 13.7 & 100.0 \\
\hline Total & 197 & 100.0 & 100.0 & \\
\hline
\end{tabular}

\subsection{Skills of Students use in Detecting Misinformation on COVID-19 on Social Media}

The Table 4 below illustrates the total number of the respondent which is 197 .the Table also has a frequency of each choice such as 'Informative and proper judgment' 19 (9.6\%) 'Compare information from various reliable sources' $22(11.2 \%)$ 'Wide range of reading' $10(5.1 \%)$ 'Common sense and fact-finding' $15(7.6 \%)$ 'Verifying from the main point source of information' $41(20.8 \%)$ 'Media literacy and international communication' $6(3.0 \%)$ 'Reading different sources' 13(6.6\%) 'Critical thinking' 26(13.2\%) 'Facts analysis/checks and comparisons from various sources' $23(11.7 \%$ ) 'Weekly communication by the country affected is better than outside country news' 22(11.2\%).

Table 4: Skills of students use in detecting misinformation on COVID-19 on social media

\begin{tabular}{|c|c|c|c|c|}
\hline & FREQUENCY & PERCENT & $\begin{array}{l}\text { VALID } \\
\text { PERCENT }\end{array}$ & $\begin{array}{l}\text { CUMULATIVE } \\
\text { PERCENT }\end{array}$ \\
\hline Informative and proper judgment & 19 & 9.6 & 9.6 & 9.6 \\
\hline $\begin{array}{l}\text { Compare information from various } \\
\text { reliable sources }\end{array}$ & 22 & 11.2 & 11.2 & 20.8 \\
\hline Wide range of reading & 10 & 5.1 & 5.1 & 25.9 \\
\hline Common sense and fact-finding. & 15 & 7.6 & 7.6 & 33.5 \\
\hline $\begin{array}{l}\text { Verifying from the main point source of } \\
\text { the information }\end{array}$ & 41 & 20.8 & 20.8 & 54.3 \\
\hline $\begin{array}{l}\text { Media literacy, international } \\
\text { communication }\end{array}$ & 6 & 3.0 & 3.0 & 57.4 \\
\hline Reading different sources & 13 & 6.6 & 6.6 & 64.0 \\
\hline Critical thinking & 26 & 13.2 & 13.2 & 77.2 \\
\hline $\begin{array}{l}\text { Facts analysis/checks and comparisons } \\
\text { from various sources }\end{array}$ & 23 & 11.7 & 11.7 & 88.8 \\
\hline $\begin{array}{l}\text { Weekly communication by the country } \\
\text { affected is better than outside country } \\
\text { news. }\end{array}$ & 22 & 11.2 & 11.2 & 100.0 \\
\hline TOTAL & 197 & 100.0 & 100.0 & \\
\hline
\end{tabular}

\subsection{Students Description of the Current Messages about COVID-19 in Social Media}

Table 5 of the study shows the total respondents and the frequency of choice made. The data is presented in descending order as follows 'Misinformation and Fake news'63 with the percentage of 32.0. Next is 'Misinformation, Fake news and Memes'52 with a percentage of 26.4, then 'Misinformation'44 with a percentage of 22.3 next is 'Fake news' 10 with a percentage of 5.1 , ' Credible information' 10 with a percentage of 5.1 then 'Memes' 8 with a percentage of 4.1, next is ' Disinformation' 6 with a percentage of 3.0 the lastly is 'Malinformation'4 with a percentage of 2.0 . 


\begin{tabular}{|c|c|c|c|c|}
\hline & Frequency & Percent & $\begin{array}{l}\text { Valid } \\
\text { percent }\end{array}$ & $\begin{array}{l}\text { Cumulative } \\
\text { percent }\end{array}$ \\
\hline Disinformation & 6 & 3.0 & 3.0 & 3.0 \\
\hline Misinformation & 44 & 22.3 & 22.3 & 25.4 \\
\hline Mal-information & 4 & 2.0 & 2.0 & 27.4 \\
\hline Fake news & 10 & 5.1 & 5.1 & 32.5 \\
\hline Memes & 8 & 4.1 & 4.1 & 36.5 \\
\hline Credible information & 10 & 5.1 & 5.1 & 41.6 \\
\hline Misinformation, fake news, and memes & 52 & 26.4 & 26.4 & 68.0 \\
\hline Misinformation and fake news & 63 & 32.0 & 32.0 & 100.0 \\
\hline TOTAL & 197 & 100.0 & 100.0 & \\
\hline
\end{tabular}

\subsection{Reliable Sources Students Access Information on COVID-19}

The below Table 6 of the study illustrate the total number of the respondent, which is 197.The Table also has frequency of each choice such as 'Social media' 27 (13.7\%) 'Websites' 24 (12.2\%) 'Radio' 3 (1.5\%) 'TV' 8 (4.1\%) 'Newspapers' 6 (3.0\%) 'Social media, Websites and Newspapers' 50 (25.4\%) 'Social media and websites $78(39.6 \%)$.

Table 6: Reliable sources students' access to information on COVID-19

\begin{tabular}{lllll}
\hline & Frequency & Percent & $\begin{array}{l}\text { Valid } \\
\text { percent }\end{array}$ & $\begin{array}{l}\text { Cumulative } \\
\text { percent }\end{array}$ \\
\hline Social media & 27 & 13.7 & 13.7 & 13.7 \\
Websites & 24 & 12.2 & 12.2 & 25.9 \\
Radio & 3 & 1.5 & 1.5 & 27.4 \\
TV & 8 & 4.1 & 4.1 & 31.5 \\
Newspapers & 6 & 3.0 & 3.0 & 34.5 \\
Friends and family & 1 & .5 & .5 & 35.0 \\
Social media, website, and newspapers & 50 & 25.4 & 25.4 & 60.4 \\
Social media and websites & 78 & 39.6 & 39.6 & 100.0 \\
\hline Total & 197 & 100.0 & 100.0 & \\
\hline
\end{tabular}

\section{Discussions}

\subsection{Social Media Guidelines}

Unrecognized websites are significant carriers of false information in the social media space, according to this study. Even recognized and trusted online portals most often report inaccurate news, which they usually attributed to errors. The damage caused by these unrecognized online portals in the media space with regards to the flow of misinformation can never be underemphasized. Censorship in social media platforms has been a significant problem since the emergence of the internet and social media platforms. Therefore, most countries and governments try as much as possible to pass strict laws to deal with the utilization of online content. The same can be done for websites that are not recognized by the country. A classical is how China manages its internet space. In China, not every media space that intrudes the system is, but they make sure the system reports accurate and truthful news which benefits the masses in the country(Xu, 2014). Unrecognized online portals are mostly used to dupe people of their vulnerable, spread fake news, rig elections, or polarise the citizens of a country to toe in a particular direction, which becomes more powerful than a government. The finding from this study is backed by earlier research by (Xu, 2014; Zubair \& Qadir, 2019) who also proposed that unrecognized online portal should be closed down as a measure of controlling fake news.

Typically, during the outbreak of this epidemic COVID-19, China had to put sanctions on media portals that published unchecked stories, and this went a long way to minimize panic, had it not been this directive, all sorts of news would have been flying around unnoticed(WHO, 2020). It can be seen that respondents would have wished to have a narrow way of getting information on the COVID-19.68\% attribute their source of information to fake news while the real news sums up to about 30\%. This confirms what scholars such as(Lazer et al., 2018), which sort to agree that people really would have the wish to have limited dedicated websites where they can get their sources of information. This can be replicated to other themes in the space of media advocacy and education, where dedicated news portals can be in existence for the smooth flow of information.

The government has to monitor and control social media due to the power it carries. The respondents have an active interest in getting news from social media. This shows that social media is an authoritative source of dissemination of information. This finding from our study is clearly in line with earlier research conducted by (Zubair \& Qadir, 2019), which has shown that more youth both in developed and middle-income countries depend on social media because of the improvement in internet speed and mobile phones. Many governments find it 
difficult to regulate social media in this regard for the fact that it has no laws regulating them. Still, swift law enactment can give governments the right to monitor control and evaluate what should go out and what should stay. Currently, all contents are managed by the mother companies based on the enactment of laws from the country of origin.

The findings from this study clearly also show that there are inadequate policies or strategies by various institutions, including governments all over the world, to deal with fake and misinformation in social media news. Even though there are laws and policies for traditional media and its practices, social media laws and are mostly under consideration for implementations, however, the pace at which is moving is languid due to the ever-changing technologies. The only means of eliminating fake news is to devise a strategy of enacting laws to curb fake news and misinformation issues. Our findings are in line with an earlier study by(Zubair \& Qadir, 2019), who suggests that laws are crucial in combating misinformation in the online sphere.

\subsection{Digital Media Literacy}

The findings of this study recognized that one of the sources of fake news about COVID-19 was mainly social media. Hence, one of the crucial means of identifying fake COVID-19 is through a vast knowledge of the news media literacy. The research found out that for people not to be exposed to fake news and misinformation, people should detach themselves from using social media at all, thus avoiding social media. These findings are line with scholars such as (Choy \& Chong, 2019)who proposed that one way of identifying fake news is to avoid using the source of the story that does not give an accurate and reliable source of information. Although this might be a harsh solution to the digital natives, our stands propose the moderate utilization of these social platforms.

Another way of detecting fake COVID-19 news, according to this study is the cross-checking on the stories. This is the fact-checking mission that students must embark on to ascertain the genuineness of a piece of the news item. Not forwarding any information they encounter unless after cross-checking to see if it is factual. These findings from our study are also supported by (UNESCO 2018, P.70, and Funke, 2018), who acknowledged that it is always very prudent for people to cross-check a news item before forwarding for other people to consume.

The study also revealed that one best way of detecting fake news is to be informative and apply proper value judgment on news items one comes across. Logical analysis of news stories is required before evaluating the truth or otherwise of the news story. The study again suggests that another vital means of detecting fake news is through due diligence or critical thinking. Critical thinking requires that one should subject any news items to a series of logical reasoning before concluding on. These findings again are backed by a study by (Berghel 2017; Rubin et al., 2016), who indicated that individuals with critical thinking skills are less to be swayed away by misinformation in social media.

The study also found out that, analyzing, checking, and comparing from various sources are other means of detecting fake news. To ascertain whether a news item is fake or real, respondents proposed that it is also proper for people to double-check and compare any news item they come across with other reputable sources before conclusions are made on the originality of a news item. This finding confirms what scholars, such as( Recasens et al., 2013), who, in their study, cited that it is always significant for the double-check of news items before decisions are made about their consumption.

\subsection{Awareness Creation}

The finding from the study also proposes the release of timely information about the COVID-19 to prevent people from spreading fake news. The study also reports that one best means of reducing fake news and misinformation is to ensure the spread of credible information (Schmitt et al., 2018). The prevention programs like awareness creation, empowerment, and reflection are vital to fighting for misinformation and fake news in social media. It is the responsibility of the state to formulate laws to regulate social media. The different dramatic structures of social media than the previous (Allcott et al., 2018), media technologies seek for a more diverse strategy of creation of awareness. Content created by the user can be relayed without filtering or their facts being checked by editorials. Such can reach a more comprehensive reader globally when the information is misinformation. The suggestion from the respondents of this study, which is in line with the report by (WHO 2020), emphasizes the need for affected countries to be timely on their reportage on COVID-19 and the creation of awareness for broader reach. Another prescribed solution to reducing the incidence of fake news and misinformation on COVID-19, according to this study, is for agencies responsible for communication in the affected countries to daily or bi-weekly updates on the actual state of the virus. Respondents of this research believe when such actions taken by the host countries' misinformation on fake news can reduce drastically. A directive supports this finding by (WHO 2020)on measures of reducing fake news.

The global new and old media should take up the task of joining hands with different stakeholders to create awareness of the public on the COVID-19. It is paramount for this strategy to work since people tend to spread misinformation when they are not specific or know precisely what the message is. Scholars such as (Finkel et al., 2017; Schmitt et al., 2018; Wood, 2018; Lazer et al., 2018; Allcott et al., 2018) have researched misinformation 
and suggests that awareness creation play a role in minimizing the spread of misleading information which might be both fake news or misinformation. Tech giant, the Big FIVE have adapted the awareness creation strategy by embedding information on Coronavirus in there various platform (Dijck et al., 2018, pp. 7-28). This might not work effectively since not only individuals rely upon these sites for information, but also to different mass media. The convergence of these mediums could be leveraged to offer a successful solution. This is in agreement with who (Bode \& Vraga, 2017) argues that social media, when utilized at the optimum, could serve as a corrective measure(Nyhan \& Zeitzoff, 2017), to false information during epidemics, while injecting the social media campaign in correcting health misinformation globally.

The universities and general learning institutions can make use of these platforms to create awareness on the COVID-19 to lessen the current trend of misinformation and panic that is encountered in the various internet sites. This study as well supports(Bode \& Vraga, 2017; Douglas et al., 2019; Jolley \& Douglas, 2012; Lewandowsky \& Cook, 2020), on the idea of inclusivity and participation in combating pandemics.

\section{Conclusions}

The spread of misinformation and fake news on Coronavirus has led to fears not only among the people who are affected and infected but also across the world. The traditional approaches to counter these, have proven to be futile with the ever-changing social media platforms. The penetration of these technologies' utilization not only by students but also by different stakeholders make them a system that cannot be wished way in the current $21^{\text {st }}$ century. Therefore, this study contributes to the contemporary literature on the misinformation of pandemics but not limited to the Coronavirus. Although the span of the study implementation could not be used for the generalization of the findings to other related studies, it offers a piece of rich information on the student's perception of the spread of fake and misinformation in the epidemic outbreaks. The limitation of this study is underpinned by only one social media community as a sample with the heterogeneity of a particular country.

This study has demonstrated that there is still a gap to be filled in the definition of fake news and misinformation about Coronavirus. Besides, interestingly is the ability of individuals to identify misinformation online. The traditional media play a role in the debunking of the misinformation on the Internet. Hence, the study suggests the systematic convergence of these media tools to enhance the credibility of information that is disseminated. To sum up, it could be viable for the exploration and investigation of the gender and age of students and the relation in demystifying misinformation and fake news on Coronavirus in the WhatsApp and Facebook, which have come up to be the pioneers of the vice in this study.

\section{References}

Abdenour, J. (2016). Digital Gumshoes Investigative journalists' use of social media in television news reporting. Digital Journalism. https://doi.org/10.1080/21670811.2016.1175312

Allcott, H., \& Gentzkow, M. (2016). Social Media and Fake News in the 2016 Election. Journal of Economic Perspectives, 31(2), 211-236. https://doi.org/doi=10.1257/jep.31.2.211

Allcottkow, H., Gentz, M., \& Yu, C. (2018). Trends in the Diffusion of Misinformation on Social Media. https://doi.org/10.1177/2053168019848554

Al Jazeera. (2020, February 10). The doctor who warned about Coronavirus dies | China | Al Jazeera. https:/www.aljazeera.com/programmes/newsfeed/2020/02/doctor-warned-coronavirus-dies200210110130361.html

Azzimonti, M., \& Fernandes, M. (2018). Social Media Networks, Fake News, and Polarization.https://www.coalitiontheory.net/sites/default/files/annual-workshops/2018/Fernandes.pdf

Babbie, E. (2017). The Basics of Social Research (7TH ed.). Cengage Learning. https://www.google.com/books/edition

Berghel, H. (2017). Lies, Damn Lies, and Fake News. The Computer Society.

Bode, L., \& Vraga, E. K. (2017). See Something, Say Something: Correction of Global Health Misinformation on Social Media. Health Communication, 1-11. http://dx.doi.org/10.1080/10410236.2017.1331312

Bryan, C., \& Agnieszka, P. (2018). Global Cyber Security Labor Shortage and International Business Risk. IGI Global.

Bryman, A. (2012). Social research methods (4th ed). Oxford University Press.

Choy, M., \& Chong, M. (2019). Seeing Through Misinformation : A Framework for Identifying Fake Online News Director of Operations and Technology, SSON Analytics. Associate Professor, Corporate Communication (Practice), Singapore Management. 1-14. https://arxiv.org/ftp/arxiv/papers/1804/1804.03508.pdf

e-marketers. (2019). Global Social Media Statistics. www.e-marketers.org

Dijck, J. van, Poell, T., \& Waal, M. de. (2018). The Platform Society Public Values in a Connective World. Oxford University Press.

Douglas, K. M., Uscinski, J. E., Sutton, R. M., Cichocka, A., Nefes, T., Ang, C. S., \& Deravi, F. (2019). Understanding Conspiracy Theories. Advances in Political Psychology, 40(. 1), 1-33. 
https://doi.org/10.1111/pops.12568

Experts condemn "rumors and misinformation" about Coronavirus. (n.d.). Retrieved March 6, 2020, from https://www.medicalnewstoday.com/articles/experts-condemn-rumors-and-misinformation-aboutcoronavirus

FactCheck.org. (2020, February 7). Explaining Coronavirus Misinformation. FactCheck.Org. https://www.factcheck.org/2020/02/explaining-coronavirus-misinformation/

Flynn DJ, N. B. and R. J. (2017). The nature and origins of misperceptions: Understanding false and unsupported beliefs about politics. Political Psychology, 38(S1), $127-150$.

Funke D. (2018). Fact-checkers have debunked this fake news site 80 times. It's still publishing on Facebook. www.Poynter.org

Gearhart, S., \& Kang, S. (2015). Social Media in Television News: The Effects of Twitter and Facebook Comments on Journalism. 8(4), 243-259. https://doi.org/10.1177/1931243114567565

Ghosh D and Scott B. (2018). Disinformation is becoming unstoppable. 5112847. http://time.com/5112847/facebook -fake-news-unstoppable/

Finkel, J., Jiang, S., Luo, M., \& Mears, R. (2017). Fake News \& Misinformation Policy Practicum. Hewlett Foundation Madison Vincent Initiative Sheu, JD.

Herrera, S. (2020, March 4). Coronavirus Misinformation Lives Online, Despite Efforts to Stamp It Out. Wall Street Journal. https://www.wsj.com/articles/coronavirus-misinformation-lives-online-despite-efforts-tostamp-it-out-11583272556

Jolley, D., \& Douglas, K. M. (2012). The social consequences of conspiracism: Exposure to conspiracy theories decreases intentions to engage in politics and to reduce one's carbon footprint. British Journal of Psychology, 1-22. https://doi.org/10.1111/bjop.12018

Jolley, D., Meleady, R., \& Douglas, K. M. (2019). Exposure to intergroup conspiracy theories promotes prejudice, which spreads across groups. British Journal of Psychology. https://doi.org/10.1111/bjop.12385

Kaur, H. (2020, March 5). Coronavirus myths and misinformation, debunked. CNN. https://www.cnn.com/2020/03/04/health/debunking-coronavirus-myths-trnd/index.html

Kemp, S. E., Hort, J., \& Hollowood, T. (2018). Descriptive Analysis in Sensory Evaluation. John Wiley \& Sons.

Kovic, M., \& Füchslin, T. (2018). Probability and conspiratorial thinking. WILEY. https://doi.org/10.1002/acp.3408

Lazer, D. M. J., Baum, M. A., Benkler, Y., Berinsky, A. J., \& Greenhill, K. M. (2018). The science of fake news. American Association for the Advancement of Science, 359(6380), 1094-1096. https://doi.org/10.1126/science.aao2998

Lewandowsky, S., \& Cook, J. (2020). The Conspiracy Theory Handbook. http://sks.to/conspiracy.

Ndlela, M. N., \& Mano, W. (2020). Social Media and Elections in Africa, Volume 1: Theoretical Perspectives and Election Campaigns. Springer Nature.

NewsWhip. (2018). Navigating the Facebook algorithm change: 2018 report. https:/growthhackers.com/articles/navigating-the-facebook-algorithm-change-2018-report-by-newswhip

Nyhan, B., \& Zeitzoff, T. (2017). Fighting the Past: Perceptions of Control, Historical Misperceptions, and Corrective Information in the Israeli-Palestinian Conflict. Political Psychology, $\mathrm{xx}(\mathrm{xx}), 1-21$. https://doi.org/10.1111/pops.12449

O’Connor, C., \& Weatherall, J. O. (2019). The Misinformation Age: How False Beliefs Spread. Yale University Press.

Presser, S., Rothgeb, J. M., Couper, M. P., Lessler, J. T., Martin, E., Martin, J., \& Singer, E. (2004). Methods for Testing and Evaluating Survey Questionnaires. John Wiley \& Sons.

Prooijen, J. Van, \& Douglas, K. M. (2017). Conspiracy theories as part of history: The role of societal crisis situations. 10(3), 1-25. https://doi.org/10.1177/1750698017701615

Recasens, M., Cristian-Mizil, D.-N., \& Jurafsky, D. (2013). Linguistic Models for Analyzing and Detecting Biased Language. Association for Computational Linguistics.

Romm, T. (2020, March 2). Fake cures and other coronavirus conspiracy theories are flooding WhatsApp, leaving governments and users with a 'sense of panic.' WashingtonPost. https:/www.washingtonpost.com/technology/2020/03/02/whatsapp-coronavirus-misinformation/

Rubin, V. L., Conroy, N. J., Chen, Y., \& Cornwell, S. (2016). Fake News or Truth? Using Satirical Cues to Detect Potentially Misleading News. 7-17.

Schmitt, J. B., Rieger, D., \& Ernst, J. (2018). Critical Media Literacy and Islamist Online Propaganda: The Feasibility, Applicability, and Impact of Three Learning Arrangements. 12, 1-19. https://doi.org/10.4119/UNIBI/ijcv.642

Singh, K. (2007). Quantitative Social Research Methods. Sage Publications India Pvt Ltd.

Spohr, D. (2017). Fake news and ideological polarization: Filter bubbles and selective exposure on social media. Business Information Review, 34((3)), 150-160. https://doi.org/10.1177/0266382117722446 
Stimson, R. (2014). Handbook of Research Methods and Applications in Spatially Integrated Social Science. Edward Elgar Publishing.

Statista. (2019). World Social Media Statistics. www.Statista.com

UNESCO. (2018). Journalism, ' Fake News' \& Handbook for Journalism Education and Training. the United Nations Educational, Scientific and Cultural Organization, 7, place de Fontenoy, 75352 Paris 07 SP, France. http://www.unesco.org/open-access/terms-use-ccbysa-en

WHO.(2020,January28).Coronavirus(COVID-19). https://web.archive.org/web/20200128190509/https://www.who.int/emergencies/diseases/novelcoronavirus-2019

Wood, M. J. (2018). Propagating and Debunking Conspiracy Theories on Twitter during the 2015-2016 Zika Virus Outbreak. Cyberpsychology, Behavior, and social networking, 21, 1-6. https://doi.org/10.1089/cyber.2017.0669

$\mathrm{Xu}$, B. (2014). Backgrounders Media Censorship in China. 1-6. http://www.cfr.org/china/media-censorshipchina/p11515

Zubair, T., \& Qadir, J. (2019). On Combating Fake News, Misinformation, and Machine Learning Generated Fakes : Insights from the Islamic Ethical Tradition. October. https://www.researchgate.net/publication/336604412 